\title{
Responding in a time of crisis: Assessing Extension efforts during COVID-19
}

\author{
L. Narine ${ }^{1}$, C. Meier ${ }^{2}$
}

\begin{abstract}
Extension was forced to rapidly adjust its efforts and program delivery methods to respond to clientele needs during the COVID-19 pandemic of 2020. The pandemic presents a range of unique challenges to Extension including revisions to resource allocations and shifts in programmatic focus. Guided by a needs assessment framework, this paper assesses the rapid response of Utah State University (USU) Extension to meet residents needs during COVID-19. This correlational study gathered data from 199 Extension professionals $(n=199)$ at USU Extension. Findings show Extension professionals had good capacity to implement outreach activities related to online education, engaging residents, and external partnerships. Further, Extension took rapid actions in several areas in response to COVID-19, including providing online learning activities for youth, and conducting online classes in place of traditional face-to-face classes. Findings show professionals' outreach capacity was positively related to the total number of actions taken in response to COVID-19. Extension professionals addressed COVID-19 topics such as telehealth, temporary homeschooling kids, and stress management. This study demonstrates the adaptability of Extension to an unpredictable event and provides a framework to assess response. Findings are geared towards effective resource allocation to support Extension's role in meeting residents' needs during COVID19.
\end{abstract}

\section{Keywords}

Organizational capacity; emergency response; needs assessment

1. Lendel K. Narine, Extension Assistant Professor and Evaluation Specialist, Utah State University 4900 Old Main Hill, Logan, UT 84322 Lendel.Narine@usu.edu, https://orcid.org/0000-0001-6962-2770

2. Cristian Meier, Assistant Professor and Extension Community Resource and Economic Development Specialist, Utah State University

0730 Old Main Hill, Logan, UT 8431

Cris.Meier@usu.edu, https://orcid.org/0000-0001-6328-4272 


\section{Introduction and Problem Statement}

Cooperative Extension is an important resource for communities to access evidence-based information and programming (Dunifon et al., 2004). Extension typically focuses on three main programmatic areas: (a) Family and Consumer Sciences, (b) 4-H and Youth Development, and (c) Agriculture and Natural Resources. Some states have expanded their programming focus to address emerging issues such as personal health and wellbeing (Walsh et al., 2018). Countylevel programs facilitated by Extension professionals are often a trusted source of information for community members (Settle et al., 2017). As the landscape of both rural and urban communities evolve, Extension has sought to remain relevant and meet the needs of communities through periodical needs assessments and timely programmatic adaption. However, in February of 2020, the needs of communities rapidly changed due to the emergence of a global pandemic.

The novel coronavirus disease, COVID-19, has drastically impacted the lives of people internationally and locally in the United States (U.S.). COVID-19 is highly infectious and is spread from person to person via droplets from sneezes or coughs (Heymann \& Shindo, 2020). To slow the spread of COVID-19, municipalities, counties, and states have instituted measures to improve social distancing, including closing schools and encouraging people to work remotely. During this time of uncertainty, Extension can act as an important resource to help people adapt to new life circumstances such as home schooling and unemployment. Notably, there has not been a global public health event to this scale since the 1918 influenza pandemic, and the ability and readiness of Extension to act rapidly in such an event is unknown. Therefore, this paper assesses the rapid response of Utah State University (USU) Extension to meet residents needs during COVID-19.

\section{Theoretical and Conceptual Framework}

The framework guiding this study is a needs assessment (Boyle, 1981; Kaufman \& English, 1979; Kaufman \& Guerra-Lopez, 2013; Kaufman et al., 1993; Leigh et al., 2000; Witkin \& Altschuld, 1995). A need is commonly described as the difference or gap between "what is" and "what should be" (Witkin \& Altschuld, 1995, p. 9). Needs assessments are widely used across fields and its use has been well-documented as a starting point for intervention at all levels - macro and micro (Baker et al., 2012; Forrest et al., 2004; Loscalzo et al., 2017; Moreland et al., 2009).

Witkin and Altschuld (1995) defined three levels of a need that exist either within a system or external to a system. At Level 1, needs of the service receivers or primary end-users are of focus. In Extension, a Level 1 needs assessment examines the needs of clientele. Level 2 focuses on needs of service providers and administrators. At a secondary level, it considers the ability of service providers to perform functions related to serving primary end-users. In Extension, a Level 2 needs assessment may focus on the needs of Extension educators. A Level 3 needs assessment considers organizational resources and conditions such as technology infrastructure 
and facilities. A Level 3 needs assessment in Extension might focus on gaps in education and information technology for program delivery.

Based on Witkin and Altschuld's description of levels of needs, we focus on Level 2 needs by assessing the capacity of Extension professionals to serve clientele during COVID-19 pandemic of 2020. As a Level 2 assessment, findings provide information to identify and prioritize professional development needs. This framework is a systematic approach to assessing the needs of an organization to inform priorities, decision making, and improvement of allocation of resources at an organizational or system-wide level (Witkin \& Altschuld, 1995).

Needs assessment is a common starting point for organizations to make data-informed decisions to prioritize problems and identify unmet needs (Leigh et al., 2000). A comprehensive needs assessment is conceptualized as a three-phase process (a) pre-assessment, (b) assessment, and (c) post-assessment (Witkin \& Altschuld, 1995). During the pre-assessment phase, areas of concern are identified often using secondary data. This helps delineate the purpose of the needs assessment. In the assessment phase, primary data is gathered and analyzed to reveal priorities. Finally, during the post-assessment actions plans are formulated based on findings from the assessment phase. In the current study we utilized the three phases to assess organizational response to COVID-19 and provide recommendations to improve or sustain existing efforts.

\section{Purpose}

The purpose of this study was to assess USU Extension's response to the COVID-19 pandemic of 2020. To accomplish this purpose, four research objectives guided this study:

1. Assess Extension professionals' capacity to implement outreach activities during COVID-19.

2. Describe changes in outreach actions taken by Extension in response to COVID-19.

3. Determine the relationship between professional capacity and overall outreach actions taken at the beginning of COVID-19.

4. Describe Extension professionals' access to knowledge resources on topics directly related to COVID-19.

\section{Methods}

This correlational study gathered data from Extension professionals at USU Extension. The study was deemed exempt by the IRB at USU. The target population was all university professionals with an active Extension appointment (FY 2020), including specialists, program coordinators, program leaders, county faculty, and SNAP-Ed employees $(N=275)$. A census was attempted using an internal sampling frame of Extension employees. With a response rate of $72 \%$, the final sample size was 199 faculty $(n=199)$. Data were collected in March of 2020 using a researcher-developed questionnaire administered through Qualtrics. A limitation of the methodology is the use of cross-sectional data since COVID-19 is evolving at a rapid rate. 
However, our findings provide a snapshot of Extension's immediate response during the early stages of the 2020 COVID-19 pandemic in the U.S.

\section{Instrumentation}

Questionnaire development followed Dillman et al. (2014) tailored design approach with respect to crafting close-ended questions. Two Extension Specialists, three Extension Directors, and the Associate Vice President for Extension reviewed the questionnaire for validity. Further, a post-assessment of reliability was assessed through the Cronbach's Alpha. The final questionnaire consisted of three sections: (a) Individual Capacity - Extension professionals' perception towards their capacity to meet residents' needs, (b) Actions - outreach actions in response to COVID-19, and (c) Knowledge Resources - professionals' access to knowledge resources on COVID-19 topics.

To assess capacity in Section 1, respondents were presented with a brief description of organizational capacity: Capacity relates to existing human, financial, technological, and administrative resources (Cox et al., 2018). After, they were asked to rate their own capacity to perform 10 action items (e.g., conduct effective online classes, and partner with other governmental organizations to coordinate efforts) on a five-point scale: $1=$ Terrible, $2=$ Poor, 3 $=$ Average, $4=$ Good, and $5=$ Excellent. In Section 2, respondents were asked to indicate if they implemented 10 outreach activities aligned to capacity items in section one during COVID-19 on a three-point scale; 1 = I do not plan to, $2=1$ plan to, and $3=$ Yes. They were also asked if they implemented these strategies before COVID-19 using a three-point scale as follows: $1=$ No, $2=$ Sometimes, 3 = Yes. In Section 3, Extension professionals were asked if they had the knowledge resources needed to address 20 educational topics (e.g., remote work, mental health, selfdistancing) related to COVID-19 $(1=N o, 2=Y e s)$. Knowledge resources referred to credible educational material on the topic for use in Extension programming. In addition, respondents were asked if they were currently addressing the topic in their programming ( $1=$ I do not plan to, 2 = I plan to, 3 = Yes, 0 = Not Applicable).

\section{Data Analysis}

Data were analyzed using descriptive statistics, Principal Component Analysis (PCA), and bivariate correlations. First, the list of items for outreach capacity was reduced into orthogonal constructs using a PCA. Items were organized and presented by construct in the results. For Objective 1, descriptive analysis was used to measure professionals' capacity to implement outreach actions. A Point-Score (PS) was calculated from each item's frequency distribution to allow inter-item rankings. PS was calculated as follows: PS $=[(1 * \%$ Terrible $)+(2 * \%$ Poor $)+(3$ * \% Average $)+(4 * \%$ Good $)+(5 * \%$ Excellent $)]$. The PS was standardized between 0 and 1 , with values approaching 1 signaling higher capacity to implement an outreach action. Interpretation of the PS were based on an even distribution of the original five-point scale; 0 $0.20=$ Terrible $; 0.21-0.40=$ Poor $; 0.41-0.60=$ Average $; 0.61-0.80=$ Good $; 0.81-1=$ Excellent.

For Objective 2, the net change in outreach actions was calculated as a percentage change in implementation before and during COVID-19. Spearman's rho was used to determine exiting 
relationships between capacity areas and overall outreach actions for Objective 3 . The null hypothesis for the Spearman's test was rejected at $p<0.05^{*}$. Objective 4 was addressed using descriptive statistics. Further, a Sharing Gap percentage score was calculated to show the difference in knowledge resources for respondents who were already addressing COVID-19 topics $(A)$ and those who planned to address $(P)$ these topics in future programming (Sharing Gap = P - A).

\section{Findings}

A descriptive analysis of the sample revealed respondents mostly identified as county faculty $(45 \%, n=90)$. Others were specialists $(23 \%, n=46)$, staff, which includes SNAP-Ed employees, program coordinators $(21 \%, n=42)$, and program leaders $(11 \%, n=21)$. About $36 \%$ of respondents indicated their major programming area was Agriculture and Natural resources, 20\% stated $4-\mathrm{H}$ and Youth Development, 19\% indicated Family and Consumer Sciences, and $25 \%$ of respondents selected "Other" for their primary programming area. An assessment of the open-ended text response to "Other" indicated many respondents split their times across the three major programmatic areas. Further, internal data indicated approximately $80 \%$ of Extension-funded employees at USU perform some level of programming related to $4-\mathrm{H}$ and Youth Development.

\section{Objective 1: Capacity for Outreach During COVID-19}

A PCA was used to reduce 10 outreach capacity items into latent constructs. Using an orthogonal rotation, three factors had eigen values greater than one, and the scree plot confirmed all three factors explained enough variance for extraction. The PCA was valid since the Kaiser-Meyer-Olkin Measure of Sampling Adequacy (KMO) was 0.83 and the Bartlett's Test of Sphericity was significant $\left(X^{2}=950.76, p<0.001^{* *}\right)$. Together, the three factors explained $72 \%$ of variance in the original list of capacity items. The extracted factors were referred to as Factors of Outreach Capacity and described as follows; (a) Online Education, (b) Engaging Residents, and (c) External Partnerships. As shown in Table 1, all Factors of Outreach Capacity had acceptable internal consistency based on the Cronbach's Alpha $(\alpha)$. Online Education refers to actions taken to create online learning courses in Extension. Engaging Residents relate to delivering educational content to Extension audiences. External Partnerships refer to working with non-Extension agencies for information delivery and coordinating efforts.

Table 1 shows a descriptive summary of respondents' self-assessed capacity to implement outreach actions grouped by Factors of Outreach Capacity. Results indicated Extension professionals had good capacity to implement tasks related to Online Education ( $P S=0.63$ ). Descriptive frequencies indicated about $20 \%$ of respondents had excellent capacity to conduct effective online classes, and $15 \%$ had excellent capacity to convert face-to-face classes to online classes. Extension professionals also had good capacity to implement task related to engaging residents ( $P S=0.69$ ). About $42 \%$ of respondents had excellent capacity to provide residents with updates via email, text, or other methods, and $33 \%$ had excellent capacity to connect 
frequently with residents through social media. Finally, results indicated professionals had good capacity to perform tasks for External Partnerships $(P S=0.70)$. Descriptive results indicated $33 \%$ of respondents had excellent capacity to partner with other governmental organizations to coordinate efforts, and $29 \%$ had excellent capacity to communicate with local leaders about addressing the needs of residents.

Table 1

Professionals' Capacity to Implement Factors of Outreach Capacity

\begin{tabular}{|c|c|c|c|c|c|c|}
\hline \multirow{2}{*}{ Task } & \multicolumn{5}{|c|}{$\%(n=199)^{*}$} & \multirow{2}{*}{$\mathrm{PS}^{\wedge}$} \\
\hline & $T$ & $P$ & $A$ & G & $E$ & \\
\hline Online Education ( $\alpha=.92$ ) & & & & & & 0.63 \\
\hline Conduct effective online classes & 1 & 11 & 32 & 36 & 20 & 0.66 \\
\hline Convert traditional face-to-face classes to online classes & 2 & 10 & 39 & 35 & 15 & 0.64 \\
\hline Creating new online classes & 2 & 15 & 37 & 29 & 17 & 0.61 \\
\hline Engaging Residents ( $\alpha=.74)$ & & & & & & 0.69 \\
\hline $\begin{array}{l}\text { Contact residents to provide updates (via email, text, or other } \\
\text { methods) }\end{array}$ & 2 & 4 & 12 & 40 & 42 & 0.79 \\
\hline Connect frequently with residents through social media & 6 & 11 & 24 & 27 & 33 & 0.68 \\
\hline Provide online learning activities for youth & 5 & 18 & 33 & 26 & 18 & 0.59 \\
\hline External Partnerships $(\alpha=.71)$ & & & & & & 0.70 \\
\hline $\begin{array}{l}\text { Partner with other governmental organizations to coordinate } \\
\text { efforts }\end{array}$ & 2 & 4 & 24 & 37 & 33 & 0.74 \\
\hline $\begin{array}{l}\text { Communicate with local leaders about how your office/team } \\
\text { can support or address the needs of residents }\end{array}$ & 1 & 3 & 29 & 37 & 29 & 0.72 \\
\hline $\begin{array}{l}\text { Partner with nongovernmental emergency response } \\
\text { organizations }\end{array}$ & 3 & 10 & 27 & 35 & 26 & 0.69 \\
\hline Provide information to news and media outlets & 2 & 10 & 33 & 32 & 23 & 0.66 \\
\hline
\end{tabular}

*Note. $\mathrm{T}=$ Terrible, $\mathrm{P}=$ Poor, $\mathrm{A}=$ Average, $\mathrm{G}=$ Good, $\mathrm{E}=$ Excellent

\section{Objective 2: Rapid Actions in Extension during COVID-19}

Table 2 provides a description of rapid actions taken by Extension within the first two weeks of COVID-19 in Utah. Retrospective before-and-after comparisons were made to highlight changes in actions before and during COVID-19. The net change in actions represents the responsiveness of Extension to the initial pandemic outbreak in Utah. Results indicated substantial changes to youth programming; $29 \%$ of professionals provided online learning activities for youth during COVID-19 compared to only $9 \%$ of respondents before COVID-19. This signals a $222 \%$ increase in online learning activities for youth before and during COVID-19. In addition, substantial changes were recorded for conducting online classes in place of traditional face-to-face classes ( $207 \%$ increase) and learning how to conduct online classes (125\% increase). 
Table 2

Main Actions Taken by Extension in Response to COVID-19

\begin{tabular}{|c|c|c|c|}
\hline \multirow[b]{2}{*}{ Action } & \multicolumn{2}{|c|}{$\%(n=199)$} & \multirow{2}{*}{$\begin{array}{c}\% \text { Net } \\
\text { Change* }\end{array}$} \\
\hline & $\begin{array}{l}\text { Yes- } \\
\text { Before }\end{array}$ & $\begin{array}{l}\text { Yes - } \\
\text { During }\end{array}$ & \\
\hline Providing online learning activities for youth & 9 & 29 & 222 \\
\hline $\begin{array}{l}\text { Conducting online classes in place of traditional face-to-face } \\
\text { classes }\end{array}$ & 14 & 43 & 207 \\
\hline Learning how to conduct online classes & 24 & 54 & 125 \\
\hline Connecting frequently with residents through social media & 45 & 56 & 24 \\
\hline Creating new online classes & 22 & 26 & 18 \\
\hline $\begin{array}{l}\text { Partnering with non-governmental emergency response } \\
\text { organizations }\end{array}$ & 22 & 26 & 18 \\
\hline $\begin{array}{l}\text { Contacting residents to provide updates (via email, text, or } \\
\text { other methods) }\end{array}$ & 58 & 58 & 0 \\
\hline $\begin{array}{l}\text { Communicating with local leaders about how your } \\
\text { office/team can support or address the needs of residents }\end{array}$ & 51 & 48 & -6 \\
\hline Providing information to news and media outlets & 31 & 28 & -10 \\
\hline $\begin{array}{l}\text { Partnering with other governmental organizations to } \\
\text { coordinate efforts }\end{array}$ & 52 & 47 & -10 \\
\hline
\end{tabular}

${ }^{*}$ Note. Net Change is the percentage change in activities before and during COVID 19

While results indicated substantial changes in most items, there were minor changes in some areas such as the creation of new online classes and partnerships with non-governmental emergency response organizations. Further, compared to before COVID-19, there were decreases in communicating with local leaders about supporting or addressing the needs of residents $(-6 \%)$, providing information to news and media outlets $(-10 \%)$, and partnering with other governmental organizations to coordinate efforts (-10\%) during COVID-19.

\section{Objective 3: Role of Factors of Outreach Capacity on Rapid Actions}

Bivariate correlations between Factors of Outreach Capacity and rapid actions were assessed using the Spearman's rho coefficient $(\rho)$. This analysis indicated how changes in Factors of Outreach Capacity $(i=3)$ corelated to the total number of rapid actions $(i=10)$ taken by Extension in response to COVID-19. Results indicated online education was weakly, but significantly correlated to the total number of actions taken by Extension $\left(\rho=.35, p<0.001^{* *}\right)$. Also, there were moderate and significant correlations between the total number of actions taken, engaging residents $\left(\rho=.45, p<0.001^{* *}\right)$, and external partnerships $\left(\rho=.49^{* *}, p<\right.$ $\left.0.001^{* *}\right)$. Based on the correlation coefficients, all Factors of Outreach Capacity were positively related to the total number of rapid actions taken by Extension. This indicates as Extension professionals' capacity to conduct online education, engage with residents, and form external partnerships increased, there was an increase in the total number of actions taken by Extension during COVID-19 in March of 2020. 


\section{Objective 4: Knowledge Resources}

Table 3 provides a descriptive summary of the availability of knowledge resources to address topics directly related to COVID-19. Results indicated all respondents (100\%) who were already addressing mental health, grocery shopping during COVID-19, self-distancing, sheltering in place, self-quarantine, disinfecting surfaces, emergency preparedness, 72-hour kits and finding reliable information on COVID-19 in their programming had access to the necessary knowledge resources. Overall, findings in Table 3 demonstrates most respondents (>94\%) who were already addressing COVID-19 topics in their programming had access to the necessary knowledge resources on the topics.

In contrast, there were less knowledge resources among professionals who planned to address COVID-19 topics in their Extension programming. For example, while $96 \%$ of respondents who were already addressing telehealth had access to the necessary knowledge resources on the topic, only $68 \%$ of those who planned to address it had access to the knowledge resource. Similarly, $94 \%$ of those already addressing temporary homeschooling had access to the knowledge resources, but only $70 \%$ of respondents who planned to address the topic had access the knowledge resource for the topic. This highlights a gap in knowledge resources; the Sharing Gap in Table 3 shows a discrepancy in knowledge resources between those who were already addressing COVID-19 topics $(A)$ and those who planned to address the topic $(P)$. While this gap existed for most topic areas, the widest discrepancies were telehealth (-28\%), temporary homeschooling kids (-24\%), stress management $(-15 \%)$, and remote work $(-15 \%)$. 
Table 3

Knowledge Resources for COVID-19 Educational Programming

\begin{tabular}{|c|c|c|c|}
\hline \multirow[b]{2}{*}{ Topic } & \multicolumn{2}{|c|}{ Knowledge Resources [\%, $(n)]$} & \multirow{2}{*}{$\begin{array}{c}\text { Sharing } \\
\text { Gap } \\
(\mathrm{P}-\mathrm{A})\end{array}$} \\
\hline & $\begin{array}{c}\text { Already } \\
\text { addressing }(A)\end{array}$ & $\begin{array}{l}\text { Plan to Address } \\
(P)\end{array}$ & \\
\hline Telehealth & $96(26)$ & $68(15)$ & -28 \\
\hline Temporary homeschooling kids & $94(31)$ & $70(19)$ & -24 \\
\hline Stress management & $98(55)$ & $83(35)$ & -15 \\
\hline Remote work & $98(77)$ & $83(20)$ & -15 \\
\hline Mental health & $100(53)$ & $88(29)$ & -12 \\
\hline Grocery shopping during COVID-19 & $100(29)$ & $89(23)$ & -11 \\
\hline Financial management during COVID-19 & $96(25)$ & $86(25)$ & -10 \\
\hline Self-distancing & $100(86)$ & 91 (19) & -9 \\
\hline Sheltering in place & $100(52)$ & $92(35)$ & -8 \\
\hline Steps to slow infections & $99(64)$ & $93(26)$ & -6 \\
\hline Self-quarantine & $100(56)$ & $94(31)$ & -6 \\
\hline Spread of COVID-19 & $97(60)$ & $92(22)$ & -5 \\
\hline Disinfecting surfaces & $100(67)$ & $96(24)$ & -4 \\
\hline Handwashing & $99(77)$ & $96(24)$ & -3 \\
\hline Personal hygiene & 99 (69) & $96(25)$ & -3 \\
\hline Emergency preparedness & $100(37)$ & $97(36)$ & -3 \\
\hline 72-hour kits & $100(22)$ & $97(32)$ & -3 \\
\hline Looking for online learning opportunities & $99(81)$ & $97(38)$ & -2 \\
\hline Finding reliable information on COVID-19 & $100(49)$ & $100(35)$ & 0 \\
\hline
\end{tabular}

\section{Conclusions, Discussion, and Recommendations}

COVID-19 is actively affecting residents across the nation. Extension's response to the everevolving situation is dependent on its ability to rapidly adapt to meet residents' needs. While it is unclear how other land grant institutions are responding to COVID-19, this paper provides a snapshot of the actions taken by USU Extension to meet residents needs during the COVID-19 pandemic. Guided by the three-phase needs assessment framework (Witkin \& Altschuld, 1995), we examined USU Extension's capacity, actions, and knowledge resources in response to the COVID-19 pandemic. These priority areas were defined by organization leadership during the pre-assessment phase. Overall, results found in the assessment phase showed Extension professionals in Utah had good outreach capacity, they rapidly implemented several actions in response to COVID-19, and their self-assessed outreach capacity was positively related to total number of rapid actions taken. Further, findings highlighted a gap in knowledge resources between professionals who were actively engaged in COVID-19 related programming and those who planned to implement such programming. 
The assessment results provide actionable steps that could be taken by USU Extension during the post-assessment phase (Witkin \& Altschuld, 1995) and describes implications for the larger Cooperative Extension system's response to COVID-19. First, Extension's capacity to act in the time of crisis or during an emergency is dependent on its existing employees and their willingness to adapt to changing situations. In this study, we found that Extension professionals reported adequate capacity to create online education, engage and communicate with residents, and work with external partnerships to coordinate efforts and disseminate information in response to COVID-19. Capacity is important to helping organizations achieve their mission (Connolly \& Lukas, 2002), and increasing capacity can help organizations improve the work they already do, contribute to expansion efforts, and to meet the changing needs of residents (Letts et al., 1999). While self-assessed capacity was generally good, we suggest USU Extension use the results of our study to develop a professional development plan to further improve Extension professional capacity to respond and adapt programming during a crisis. Other Extension institutions could utilize a similar factor analysis (Abdi \& Williams, 2010) process to identify key capacity areas and utilize Point Scores to inform and prioritize professional development opportunities to quickly build Extension professional capacity to improve response to COVID-19.

As Extension faculty work to adapt to meet the local needs of community members, having the knowledge necessary to address these needs is vital for rapid response. In our study we found that there was a sharing gap; most Extension professionals who were already addressing a topic had enough knowledge resources on the topic, while far fewer Extension professionals that planned to address to topic had the knowledge resources. This sharing gap was most prominent in two topic areas, telehealth and temporary homeschooling kids. To facilitate resource sharing, we recommend that Extension leadership encourage internal and external sharing and access to knowledge resources especially in topic areas where a sharing gap is found. A cloud-based knowledge resource depository could be developed to streamline information sharing while improving Extension professional competencies to address priority topics (Demidova et al., 2007). By taking active steps to improve knowledge resource sharing, Extension could improve rapid response to the current crisis, while also be prepared for future emergency situations.

Extension's mission to provide evidence-based information and programming that meet the needs of communities suggests that Extension can plan a role in helping community members adapt daily living to follow the local, county, and state directives (e.g., social distancing) and orders (e.g., stay home) they are presented with in a time of crisis. At the state level, the results of this study can be used to improve coordinated state response and inform professional development opportunities needed to help Extension professionals effectively respond and adapt to residents' needs. Extension institutions across the U.S. can use these results to guide future actions to tackle gaps in emergency response and inform strategies for educational outreach actions during crisis situations. We suggest Extension institutions conduct their own COVID-19 response assessment to inform their delivery efforts and future responses to crisis and emergency situations. 


\section{References}

Abdi, H., \& Williams, L. J. (2010). Principal component analysis. Wiley Interdisciplinary Reviews: Computational Statistics, 2(4), 433-459. https://doi.org/10.1002/wics.101

Baker, C. J., Sinha, R., \& Sullivan, M. E. (2012). Development of a cardiac surgery simulation curriculum: from needs assessment results to practical implementation. Journal of Thoracic and Cardiovascular Surgery, 144(1), 7-16. https://doi.org/10.1016/j.jtcvs.2012.03.026

Boyle, P. G. (1981). Planning better programs. McGraw-Hill.

Connolly, P., \& Lukas, C. A. (2002). Strengthening nonprofit performance: A funder's guide to capacity building. Amherst H. Wilder Foundation.

Cox, K., Jolly, S., Van Der Staai, S., \& Van Stolk, C. (2018). Understanding the drivers of organization capacity. RAND Europe. https://www.rand.org/content/dam/rand/pubs/research_reports/RR2100/RR2189/RAN D RR2189.pdf

Demidova, E., Karger, P., Olmedilla, D., Ternier, S., Duval, E., Dicerto, M., Mendez, C., \& Stefanov, K. (2007). Services for knowledge resource sharing \& management in an open source infrastructure for lifelong competence development. International Conference on Advanced Learning Technologies, 2007, 691-693. https://ieeexplore.ieee.org/document/4281128

Dunifon, R., Duttweiler, M., Pillemer, K., Tobias, D., \& Trochim, W. M. (2004). Evidence-based Extension. Journal of Extension [On-line], 42(2) Article 2FEA2. https://www.joe.org/joe/2004april/a2.php

Forrest, S., Strange, V., Oakley, A., \& RIPPLE Study Team. (2004). What do young people want from sex education? The results of a needs assessment from a peer-led sex education programme. Culture, Health \& Sexuality, 6(4), 337-354. https://doi.org/10.1080/13691050310001645050

Heymann, D. L., \& Shindo, N. (2020). COVID-19: What is next for public health? The Lancet, 395(10224), 542-545. https://doi.org/10.1016/S0140-6736(20)30374-3

Kaufman, R. A., \& English, F. W. (1979). Needs assessment: Concept and application. Educational Technology.

Kaufman, R., \& Guerra-Lopez, I. (2013). Needs assessment for organizational success. American Society for Training and Development. 
Kaufman, R. A., Rojas, A. M., \& Mayer, H. (1993). Needs assessment: A user's guide. Educational Technology.

Leigh, D., Watkins, R., Platt, W. A., \& Kaufman, R. (2000). Alternate models of needs assessment: Selecting the right one for your organization. Human Resource Development Quarterly, 11(1), 87-93. https://doi.org/10.1002/15321096(200021)11:1<87::AID-HRDQ7>3.0.CO;2-A

Letts, C. W., Ryan, W. P., \& Grossman, A. (1999). High performance nonprofit organizations: Managing upstream for greater impact. John Wiley \& Sons

Loscalzo, E., Sterling, R. C., Weinstein, S. P., \& Salzman, B. (2017). Alcohol and other drug use in older adults: Results from a community needs assessment. Aging Clinical and Experimental Research, 29(6), 1149-1155. https://doi.org/10.1007/s40520-016-0718-z

Moreland, J. D., DePaul, V. G., DeHueck, A. L., Pagliuso, S. A., Yip, D. W., Pollock, B. J., \& Wilkins, S. (2009). Needs assessment of individuals with stroke after discharge from hospital stratified by acute Functional Independence Measure score. Disability and Rehabilitation, 31(26), 2185-2195. https://doi.org/10.3109/09638280902951846

Settle, Q., Rumble, J. N., McCarty, K., \& Ruth, T. K. (2017). Public knowledge and trust of agricultural and natural resources organizations. Journal of Applied Communications, 101(2). https://doi.org/10.4148/1051-0834.1007

Walsh, M., John, D., Peritore, N., Morris, A., Bird, C., Ceraso, M., Eichberger, S., Novotny, R., Stephenson, L., Stluka, S., \& Riportella, R. (2018). Health in all policies: Working across sectors in Cooperative Extension to promote health for all. Journal of Human Sciences and Extension, 6(2), 37-56. https://www.jhseonline.com/article/view/718/620

Witkin, B. R., \& Altschuld, J. W. (1995). Planning and conducting needs assessments: A practical guide. Sage.

(C) 2020 by authors. This article is an open access article distributed under the terms and conditions of the Creative Commons Attribution license (http://creativecommons.org/licenses/by/4.0/). 